Article

\title{
Imergard ${ }^{\mathrm{TM}}$ WP: A Non-Chemical Alternative for an Indoor Residual Spray, Effective against Pyrethroid-Resistant Anopheles gambiae (s.1.) in Africa
}

Jean M. Deguenon ${ }^{1}$, Roseric Azondekon ${ }^{2} \mathbb{D}$, Fiacre R. Agossa ${ }^{2}\left(\mathbb{D}\right.$, Gil G. Padonou ${ }^{2}$, Rodrigue Anagonou ${ }^{2}$, Juniace Ahoga ${ }^{2}$, Boris N'dombidje ${ }^{2}$, Bruno Akinro ${ }^{2}$, David A. Stewart ${ }^{3}$, Bo Wang ${ }^{3}$, David Gittins ${ }^{3}$, Larissa Tihomirov ${ }^{3}$, Charles S. Apperson ${ }^{1}$, Marian G. McCord ${ }^{4}$, Martin C. Akogbeto ${ }^{2}$ and R. Michael Roe ${ }^{1, *(\mathbb{D}}$

1 Department of Entomology and Plant Pathology, Campus Box 7647, 3230 Ligon Street, North Carolina State University, Raleigh, NC 27695, USA; jdeguen@ncsu.edu (J.M.D.); apperson@ncsu.edu (C.S.A.)

2 Centre de Recherche Entomologique de Cotonou (CREC), Cotonou 06BP2604, Benin; roseric_2000@yahoo.fr (R.A.); rofargossa@yahoo.fr (F.R.A.); pagergil@yahoo.fr (G.G.P.); rodrigue.anagonou@yahoo.fr (R.A.); meakim2015@yahoo.fr (J.A.); incas05@yahoo.fr (B.N.); akinrobruno@gmail.com (B.A.); akogbetom@yahoo.fr (M.C.A.)

3 Imerys Filtration Minerals, Inc., Roswell, GA 30076, USA; David.Stewart@imerys.com (D.A.S.); B.Wang@activeminerals.com (B.W.); David.Gittins@imerys.com (D.G.); larisa.tihomirov@imerys.com (L.T.)

4 College of Natural Resources, Campus Box 8001, 2820 Faucette Drive, North Carolina State University, Raleigh, NC 27695, USA; mmccord@ncsu.edu

* Correspondence: Michael_roe@ncsu.edu; Tel.: +1-919-515-4325

Received: 3 March 2020; Accepted: 18 May 2020; Published: 23 May 2020

\begin{abstract}
Malaria is the deadliest mosquito-borne disease and kills predominantly people in sub-Saharan Africa (SSA). The now widespread mosquito resistance to pyrethroids, with rapidly growing resistance to other insecticide classes recommended by the World Health Organization (WHO), may overturn the successes gained in mosquito control in recent years. It is of utmost importance to search for new, inexpensive, and safe alternatives, with new modes of action, that might improve the efficacy of current insecticides. The efficacy of a novel mechanical insecticidal mineral derived from volcanic rock, Imergard ${ }^{\mathrm{TM}} \mathrm{WP}$, was investigated to determine its efficacy as a stand-alone residual wall spray and as a mixture with deltamethrin (K-Othrine ${ }^{\circledR}$ Polyzone) in experimental huts in Cove, Benin. The evaluation was conducted with susceptible (Kisumu) and wild-type Anopheles gambiae (s.1.). Deltamethrin applied alone demonstrated $40-45 \%$ mortality (at $72 \mathrm{~h}$ post-exposure) during the first four months, which declined to $25 \%$ at six months for wild An. gambiae from Cove. Imergard ${ }^{\mathrm{TM}} \mathrm{WP}$ alone and mixed with deltamethrin, under the same assay conditions, produced $79-82 \%$ and $73-81 \%$ mortality, respectively, during the same six-month period. Imergard ${ }^{\mathrm{TM}} \mathrm{WP}$ met the $80 \%$ WHO bio-efficacy threshold for residual activity for the first five months with $78 \%$ residual activity at six months. Imergard ${ }^{\mathrm{TM}} \mathrm{WP}$ can be used as a mixture with chemical insecticides or as a stand-alone pesticide for mosquito control in Africa.
\end{abstract}

Keywords: mosquito; Anopheles gambiae (s.l.); malaria; Imergard ${ }^{\mathrm{TM}} \mathrm{WP}$; mechanical insecticide; pyrethroid resistance; Africa; Benin; residual wall spray

\section{Introduction}

Malaria continues to be a major life-threatening vector-borne disease globally but more so in developing countries. According to the World Health Organization (WHO), over 90\% of the 228 million 
malaria cases and 405,000 deaths observed in 2018 were recorded in Africa [1]. It is the first cause of mortality and morbidity in West Africa, and the majority of malaria-endemic countries are in sub-Saharan Africa (SSA), which shares $80 \%$ of the global malaria burden [1,2]. Malaria parasites are transmitted by infected Anopheline mosquito species. Vector control is therefore essential in the fight against malaria and is commonly accomplished through the use of insecticide-treated nets (ITNs) and indoor residual spraying (IRS) [3]. The latter consists of applying insecticides to interior walls of a house.

IRS is highly effective in controlling malaria vectors and has contributed significantly to the successes obtained in the fight against the disease in recent years [4,5]. However, insecticide resistance is now widespread for pyrethroids, one the most used insecticide classes in vector control [6-8]. More concerning is that resistance to the other classes of insecticides approved by the WHO (carbamates, organochlorines, and organophosphates) has started to rise and has now been suspected or documented in several countries worldwide [6,9-11]. It is therefore of utmost importance to search for alternatives that not only exhibit new modes of action, but are also safer, cost-effective, sustainable, naturally occurring if possible, and compatible with the synanthropic nature of mosquitoes.

Mechanical insecticides (MIs) are minerals that come into contact with insects and produce a lethal effect. MIs exhibit insecticidal properties through a physical mode of action and have consistently been shown to control numerous agricultural pests, i.e., Coleoptera [12], Thysanoptera [13], Lepidoptera [14], and Hemiptera [15]. Their potential use in public heath, on the other hand, has received minimal attention and was almost exclusively limited to laboratory trials [16,17].

In this study, we demonstrated the efficacy of a new mineral-based mosquitocide derived from volcanic rock, Imergard ${ }^{\mathrm{TM}}$ WP (expanded perlite, $100 \%$ ), in commercialization by the company, Imerys. Perlite is an aluminosilicate volcanic glass with a relatively high-water content, typically formed by the hydration of obsidian. It occurs naturally and has the unusual property of greatly expanding in volume under extreme temperature. Because of its low density, perlite is used as insulation or in plant growth media. Perlite is listed in the US Food and Drug Administration (FDA) database as Generally Recognized as Safe (GRAS), is classified as a feed additive by the European Food Safety Authority (EFSA), and is found in products like toothpaste [18]. It has not been considered before for vector control. The MI described in this paper (applied by spraying in water) provides a new mode of insecticide action for mosquito and malaria control, disrupting insect water balance. The current thinking is that mechanical insecticides disrupt the protective lipid layer of the insect's cuticle, thus leading to death by desiccation (a non-toxic, i.e., non-systemic mode of action) [16,17,19]. Because the MI is an industrial mineral, its activity does not degrade with time as long as the mechanical insecticide is present and can transfer to the insect [19]. Since mechanical insecticides have not been used before in mosquito control, it should be effective against pyrethroid-resistant mosquitoes in Africa.

We evaluated the toxicity and residual activity of Imergard ${ }^{\mathrm{TM}} \mathrm{WP}$ alone and as a mixture with deltamethrin for the control of susceptible and wild-type pyrethroid-resistant mosquitoes under field conditions in Africa. We demonstrated that the MI is a suitable alternative to a chemical insecticide currently in use for mosquito control and offers a long-lasting protection against mosquitoes such as the African malaria mosquito, Anopheles gambiae (s.l.).

\section{Materials and Methods}

\subsection{Study Site and Experimental Huts}

The study was conducted in the experimental hut station of Cove, southern Benin $\left(7^{\circ} 14^{\prime} \mathrm{N}\right.$, $2^{\circ} 18^{\prime}$ E) for six months (July to December 2017). The rice-growing fields surrounding the station provide year-round and prolific breeding sites for An. gambiae (s.1.). The local Anopheles populations are highly resistant to pyrethroids as shown from studies conducted in 2013-2014 [20] and confirmed in 2015 [21,22]. Eight experimental huts of WHO-approved West African design were used [23]. The huts were concrete experimental huts with corrugated iron roofs. The ceilings were polyethylene sheeting 
covered with palm thatch, and the interior walls were plastered with cement. Four window slits $(1 \mathrm{~cm}$ gap, 2 on the front, 2 on the sides) allowed entrance of host-seeking mosquitoes but impeded their exit, forcing them to fly towards the veranda trap on the back of the hut. A schematic of the hut can be found in Hougard et al. [24].

\subsection{Insecticide Treatments}

Four treatments were evaluated, each randomly applied ( 2 huts per treatment, 8 huts in total) as follows: (i) unsprayed, control huts, (ii) deltamethrin 62.5 SC-PE (K-Othrine ${ }^{\circledR}$ Polyzone; Bayer, Monheim am Rhein, Germany) at $25 \mathrm{mg} / \mathrm{m}^{2}$, (iii) Imergard ${ }^{\mathrm{TM}} \mathrm{WP}$ (also referred to as ImG in this paper) (Imerys, Roswell, GA, USA) at $8 \mathrm{~g} / \mathrm{m}^{2}$ as a wettable powder, and (iv) deltamethrin $62.5 \mathrm{SC}-\mathrm{PE}$ at $25 \mathrm{mg} / \mathrm{m}^{2}+$ Imergard ${ }^{\mathrm{TM}} \mathrm{WP}$ at $4 \mathrm{~g} / \mathrm{m}^{2}$. The MI was applied as a wettable powder per manufacturer's recommendations. Maximum safety instructions and protective measures were observed as a standard practice for all treatments [22]. The huts (walls and ceiling) were sprayed using a 10L Hudson Xpert compression sprayer (Hudson Xpert, Chicago, IL, USA). A mixture was conducted to test potential potentiation between Imergard ${ }^{\mathrm{TM}} \mathrm{WP}$ and a chemical insecticide.

\subsection{Sleepers and Mosquito Collection}

Eight consenting human (adult) volunteers were locally recruited and served as sleepers (mosquito collectors). They were rotated between huts on successive nights to simulate a Latin square design. They slept in the huts from 21:00 to 6:00 each night. Each morning (from 6:00), mosquitoes were collected from the huts using a mouth aspirator (main room and veranda) and transferred to the laboratory where they were identified using appropriate identification keys [25]. They were also scored as dead or alive and as fed or unfed. Mosquitoes were scored as dead if they did not move after being touched with a blunt probe. Mosquitoes were considered fed if the abdomen was visually engorged with blood. Live mosquitoes were kept in small cups, and delayed mortality was recorded for up to $72 \mathrm{~h}$ for all four treatments. Because the putative mode of action of the MI is desiccation (as mentioned earlier) and preliminary studies suggested that providing water sources in large cage tests had no impact on mortality, mosquitoes were not provided with a sugar solution during the holding period.

The data from the two huts for each treatment were pooled together, and treatment efficacy was expressed relative to the untreated control in terms of deterrence (reduction in hut entry relative to the untreated control huts), the exophily rate (proportion of mosquitoes, relative to that of the control, that were found in the exit trap (= veranda)), blood-feeding inhibition (reduction in blood feeding compared with that of the control), and delayed mortality (percentage mortality at 24, 48 , and $72 \mathrm{~h}$ post-collection).

\subsection{Residual Activity of Insecticide Treatments}

The residual activity of the different insecticide treatments was determined one week after treatment application and for each month of the trial using WHO cone bioassays [23]. Laboratory maintained susceptible female An. gambiae "Kisumu" and wild An. gambiae (s.1.) from Cove were tested. Ten mosquitoes (non-blood fed, 2-5 days old with ad libitum access to a 10\% honey-in-water solution before the transfer to cones) were introduced per cone and exposed to the walls for $30 \mathrm{~min}$ at different heights from the hut floor $(0.5,1,1.5$, and $2 \mathrm{~m})$. Mortality was then recorded at 24 and $48 \mathrm{~h}$.

\subsection{Statistical Analyses}

The raw data were managed using Microsoft Excel (Version 2016, Redmond, WA, USA). The WHO bio-efficacy threshold was used for the analyses of the residual effect [23]. Statistical analyses on deterrence, exophily, and blood feeding between the control and treatment were conducted using a two-proportion Z-test. The 95\% confidence intervals for the proportions were computed using the binomial test. Control mortality for mosquitoes entering the huts ranged from $2.4 \%$ to $4.5 \%$ at $72 \mathrm{~h}$ at each time point over six months. The control residual activity for the Kisumu strain in cone tests 
was $4.2-16 \%$ at $48 \mathrm{~h}$ over six months with the majority of observations $<5 \%$. The control residual activity of the wild population was $1.6-15 \%$ at $48 \mathrm{~h}$ with the majority $<5 \%$. Mortality rates were Abbott corrected [26]. All analyses were completed using the R statistical software (Version 3.6.1, R Foundation for Statistical Computing, Vienna, Austria) (R Development Core Team 2016) [27].

\subsection{Ethical Clearance}

The study was approved by the Ministry of Health in Benin (Comité d'Ethique Institutionnelle du CREC, Avis éthique favorable No. 03 du 07 Juillet 2017, Lettre No 231/MS/DC/SGM/DRFMT/ CREC/CEI-CREC/SA du 03 Août 2017). The human volunteer sleepers gave informed consent prior to their participation in the study.

\subsection{Abbreviations}

CREC: Centre de Recherche Entomologique de Cotonou; Delta: deltamethrin; DM, deltamethrin; EFSA: European Food Safety Authority; FDA: Food and Drug Administration; GRAS: generally recognized as safe; ImG: Imergard ${ }^{\mathrm{TM}}$ WP; IRS: indoor residual spraying; ITNs: insecticide-treated nets; MI: mechanical insecticide; NCSU: North Carolina State University; PE: polymer enhanced; SEM: scanning electron microscopy; SC: suspension concentrate; SE: standard error; WG: water dispersible granules; WHO: World Health Organization; WP: wettable powder.

\subsection{Data Availabity}

All of the data supporting the findings are presented in the paper.

\section{Results}

The efficacy of ImG (Figure 1) was evaluated in small-scale field trials in southern Benin, West Africa (Figure 2A). The MI readily mixed with water with minimal agitation and remained in suspension long enough for conducting the applications without additional agitation. Standard vector control sprayers (as described in the Materials and Methods section) without modification were adequate for the application, and Figure $2 \mathrm{~B}$ shows the $\mathrm{MI}$ applied at the rate of $8 \mathrm{~g}$ per square meter to interior hut walls and the ceiling. The product was odorless and, once applied to the wall, did not produce any obvious airborne dust. The studies were conducted using WHO-approved standard research huts (Figure 2C,D) following WHO protocols [23]. The parameters tested are presented below.

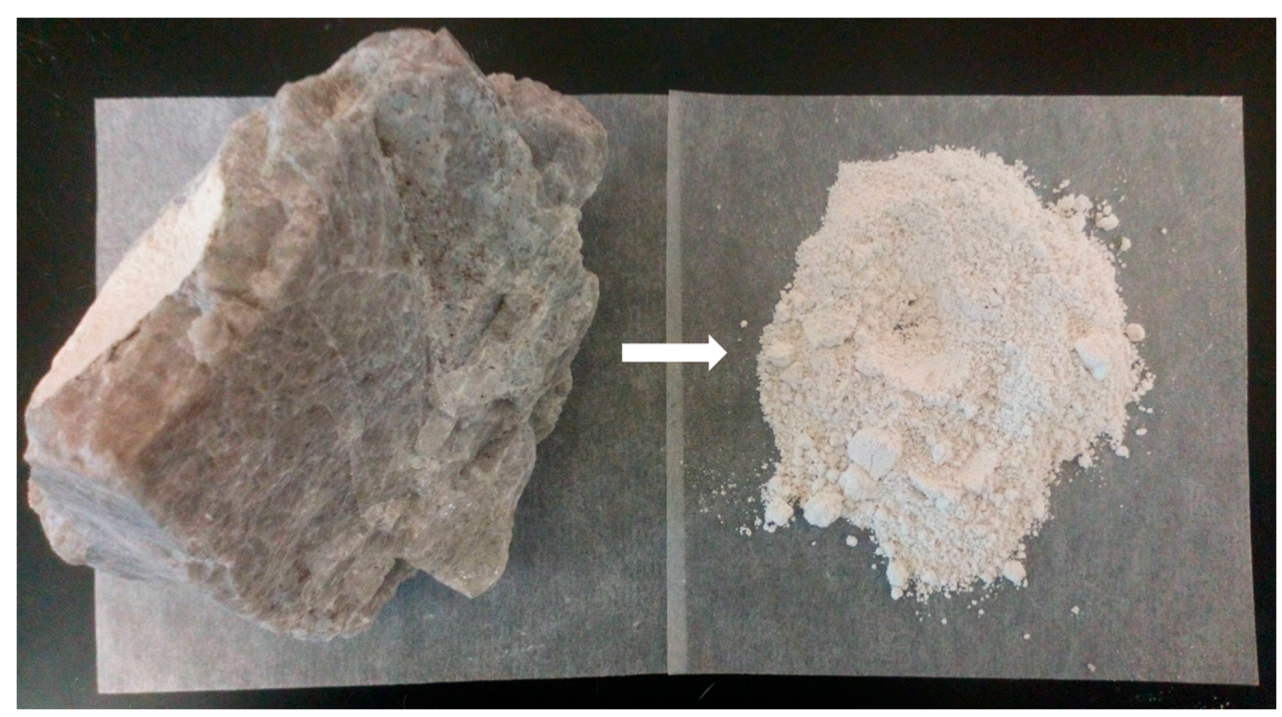

Figure 1. Imergard ${ }^{\mathrm{TM}} \mathrm{WP}$ before and after processing. Perlite, the active ingredient of Imergard ${ }^{\mathrm{TM}} \mathrm{WP}$, is a volcanic rock (left) that can be expanded (when heated to $760-980{ }^{\circ} \mathrm{C}$ ) and then processed (drying and grinding) to obtain the fine white powder used in this study (right). 


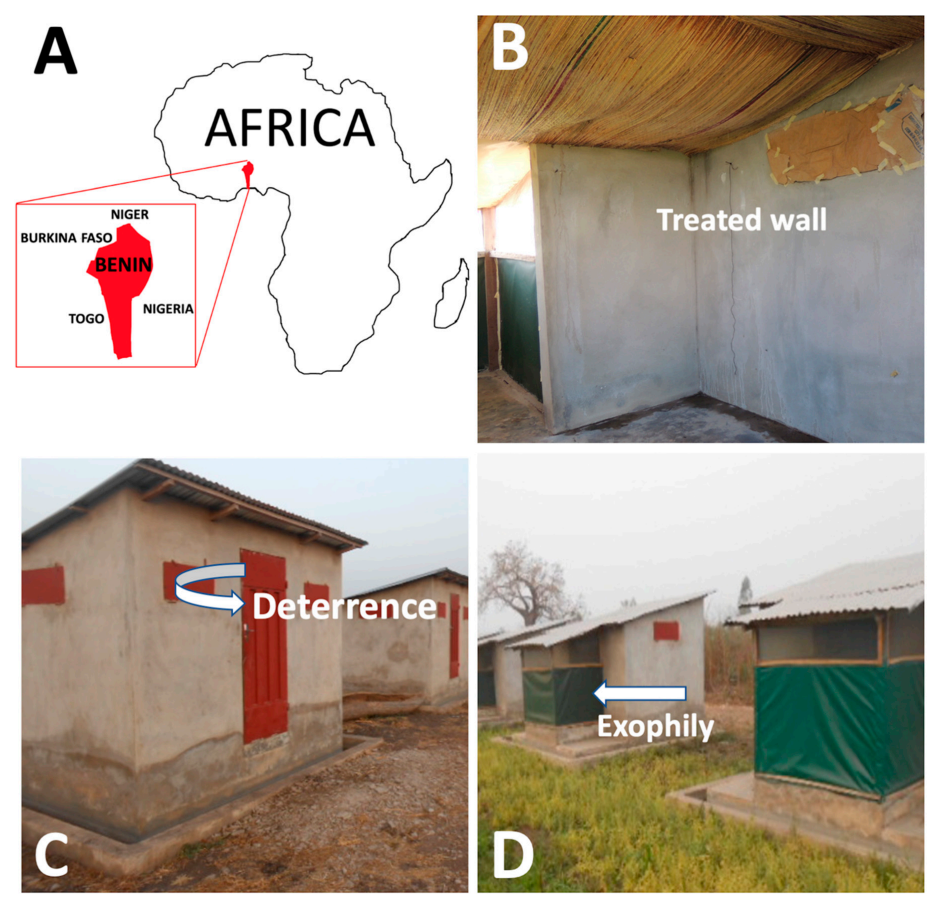

Figure 2. Study site and experimental huts: (A) location of field trial in Africa; (B) appearance of a treated wall; (C) front and side views of an experimental hut displaying the window slits for mosquito entrance as well as the movement of deterred mosquitoes; and (D) back view of a hut displaying the veranda trap as well as the exophily movement of mosquitoes that had entered the hut.

\subsection{Deterrence}

In total, 26,551 host-seeking An. gambiae (s.1.) were collected during the six-month trial. In general, and compared to the untreated control, all the treatments reduced mosquito entry at rates ranging between $8 \%$ and $39 \%$ (Table 1 ). However, this effect (Figure 2C) was highly significant $(p<0.0001$ ) and more noticeable in the huts sprayed with a mixture of ImG and deltamethrin 62.5 SC-PE where it lasted for six months (Table 1).

Table 1. Hut entry reduction in wild-type Anopheles gambiae (s.1.).

\begin{tabular}{|c|c|c|c|c|c|}
\hline Treatment & Months & Total $^{\text {a }}$ & Proportion (\%) $b$ & $95 \% \mathrm{CI}^{\mathrm{c}}$ & $p$-Value ${ }^{\mathrm{d}}$ \\
\hline \multirow[t]{6}{*}{ Control } & 1 & 785 & & & \\
\hline & 2 & 331 & & & \\
\hline & 3 & 592 & & & \\
\hline & 4 & 796 & & & \\
\hline & 5 & 2084 & & & \\
\hline & 6 & 2355 & & & \\
\hline \multirow[t]{6}{*}{ Deltamethrin } & 1 & 716 & 8.8 & $6.7-10.9$ & $<0.0001$ \\
\hline & 2 & 203 & 38.7 & $33.1-44.2$ & $<0.0001$ \\
\hline & 3 & 542 & 8.4 & $6.0-10.8$ & $<0.0001$ \\
\hline & 4 & 838 & - & - & $>0.05$ \\
\hline & 5 & 1918 & 8.0 & $6.8-9.2$ & $<0.0001$ \\
\hline & 6 & 2539 & - & - & $>0.05$ \\
\hline \multirow[t]{6}{*}{ Imergard $^{\mathrm{TM}} \mathrm{WP}$} & 1 & 645 & 17.8 & 15.0-20.6 & $<0.0001$ \\
\hline & 2 & 204 & 38.4 & $32.8-43.9$ & $<0.0001$ \\
\hline & 3 & 556 & 6.1 & $4.0-8.2$ & $<0.0001$ \\
\hline & 4 & 719 & 9.7 & $7.5-11.8$ & $<0.0001$ \\
\hline & 5 & 2098 & - & - & $>0.05$ \\
\hline & 6 & 2658 & - & - & $>0.05$ \\
\hline
\end{tabular}


Table 1. Cont.

\begin{tabular}{llllll}
\hline Treatment & Months & Total $^{\mathbf{a}}$ & Proportion (\%) $^{\mathbf{b}}$ & $\mathbf{9 5 \%}^{\mathbf{C} \mathbf{C I}^{\mathbf{c}}}$ & $\boldsymbol{p}^{\text {-Value }}$ \\
\hline DeltaM + ImG $^{\mathbf{d}}$ & 1 & 587 & 25.2 & $22.1-28.4$ & $<0.0001$ \\
& 2 & 257 & 22.4 & $17.6-27.2$ & $<0.0001$ \\
& 3 & 527 & 11.0 & $8.3-13.7$ & $<0.0001$ \\
& 4 & 678 & 14.8 & $12.2-17.4$ & $<0.0001$ \\
& 5 & 1760 & 15.6 & $13.9-17.2$ & $<0.0001$ \\
& 6 & 2163 & 8.2 & $7.0-9.3$ & $<0.0001$ \\
\hline
\end{tabular}

a Total number of mosquitoes collected in huts for each month indicated. ${ }^{b}$ Percentage reduction of mosquitoes found in treated huts compared to the number of mosquitoes found in the control; dashes represent values less than zero. ${ }^{\mathrm{C}} \mathrm{CI}$, confidence interval; dashes indicate no $\mathrm{CI}$ was calculated. ${ }^{\mathrm{d}}$ Two-proportion Z-test, $\alpha=0.05$.

${ }^{\mathrm{e}}$ Deltamethrin and Imergard ${ }^{\mathrm{TM}}$ WP mixed together and then sprayed.

\subsection{Exophily}

All treatments elicited an increased exit behavior from the mosquitoes (Figure 2D, Table 2). On average, the proportion exiting the control huts was 31\%. Exophily rates with deltamethrin 62.5 SC-PE (56\% on average) and the mixture of ImG with deltamethrin 62.5 SC-PE (50\%) were significantly $(p<0.0001)$ higher than the control huts. Exophily rates did not differ significantly between ImG $(33 \%)$ and the control $(31 \%)(p>0.05)$.

Table 2. Exophily rates ${ }^{a}$ at different times after spraying for wild-type An. gambiae (s.l.).

\begin{tabular}{|c|c|c|c|c|c|}
\hline Treatment & Months & Total $^{b}$ & Proportion ( $\%)^{a}$ & $95 \% \mathrm{CI}^{\mathrm{c}}$ & $p$-Value ${ }^{\mathrm{d}}$ \\
\hline \multirow[t]{6}{*}{ Control } & 1 & 785 & 26.9 & $23.8-30.1$ & - \\
\hline & 2 & 331 & 26.3 & $21.6-31.4$ & - \\
\hline & 3 & 592 & 31.6 & $27.9-35.5$ & - \\
\hline & 4 & 796 & 30.2 & $33.5-37.0$ & - \\
\hline & 5 & 2084 & 34.7 & $32.6-36.8$ & - \\
\hline & 6 & 2355 & 33.8 & $31.9-35.8$ & - \\
\hline \multirow[t]{6}{*}{ Deltamethrin } & 1 & 716 & 53.2 & $49.5-56.9$ & $<0.0001$ \\
\hline & 2 & 203 & 56.2 & $49.0-63.1$ & $<0.0001$ \\
\hline & 3 & 542 & 53.7 & $49.4-58.0$ & $<0.0001$ \\
\hline & 4 & 838 & 56.4 & $53.0-59.8$ & $<0.0001$ \\
\hline & 5 & 1918 & 59.8 & $57.6-62.0$ & $<0.0001$ \\
\hline & 6 & 2539 & 57.1 & $55.1-59.0$ & $<0.0001$ \\
\hline \multirow[t]{6}{*}{ Imergard } & 1 & 645 & 31.0 & $27.4-34.7$ & 0.097 \\
\hline & 2 & 204 & 34.8 & $28.1-41.6$ & 0.045 \\
\hline & 3 & 556 & 31.3 & $27.5-35.3$ & 0.966 \\
\hline & 4 & 719 & 33.2 & $29.8-36.8$ & 0.216 \\
\hline & 5 & 2098 & 33.6 & $31.5-35.6$ & 0.458 \\
\hline & 6 & 2658 & 33.5 & $31.7-35.3$ & 0.858 \\
\hline \multirow[t]{6}{*}{ DeltaM+ ImG ${ }^{\mathrm{e}}$} & 1 & 587 & 48.2 & $44.1-52.3$ & $<0.0001$ \\
\hline & 2 & 257 & 48.6 & $42.4-54.9$ & $<0.0001$ \\
\hline & 3 & 527 & 48.4 & $44.0-52.8$ & $<0.0001$ \\
\hline & 4 & 678 & 48.7 & $44.8-52.5$ & $<0.0001$ \\
\hline & 5 & 1760 & 49.9 & $47.2-52.0$ & $<0.0001$ \\
\hline & 6 & 2163 & 50.2 & $48.0-52.3$ & $<0.0001$ \\
\hline
\end{tabular}

a Percentage of mosquitoes entering the hut that were found in the veranda. ${ }^{b}$ Total number of mosquitoes collected in huts for each month indicated. ${ }^{\mathrm{C}} \mathrm{CI}$, confidence interval. ${ }^{\mathrm{d}}$ Two-proportion Z-test, $\alpha=0.05$. ${ }^{\mathrm{e}}$ Deltamethrin and Imergard ${ }^{\mathrm{TM}} \mathrm{WP}$ mixed together and then sprayed. 


\subsection{Blood Feeding}

A slight reduction in blood feeding was noticed during the 1st, 5th, and 6th months with ImG and during the 3rd, 5th, and 6th months with deltamethrin 62.5 SC-PE compared to the control (Table 3). No reduction in blood feeding was displayed by the mixture during the six-month trial (Table 3). However, it is important to point out that blood-feeding rates were in general very high across all treatments $(>90 \%)$.

Table 3. Blood-feeding rates ${ }^{a}$ of wild-type An. gambiae (s.l.) collected in the huts.

\begin{tabular}{|c|c|c|c|c|c|}
\hline Treatment & Months & Total $^{\mathbf{b}}$ & Proportion (\%) & $95 \% \mathrm{CI}^{\mathrm{c}}$ & $p$-Value ${ }^{\mathrm{d}}$ \\
\hline \multirow[t]{6}{*}{ Control } & 1 & 785 & 94.3 & $92.4-95.8$ & - \\
\hline & 2 & 331 & 95.5 & $92.6-97.6$ & - \\
\hline & 3 & 592 & 92.4 & $90.0-94.4$ & - \\
\hline & 4 & 796 & 95.5 & $93.8-96.8$ & - \\
\hline & 5 & 2084 & 97.4 & $96.6-98.0$ & - \\
\hline & 6 & 2355 & 96.1 & $95.3-96.9$ & - \\
\hline \multirow[t]{6}{*}{ Deltamethrin } & 1 & 716 & 94.8 & $92.9-96.3$ & 0.713 \\
\hline & 2 & 203 & 97.0 & $93.0-99.0$ & 0.496 \\
\hline & 3 & 542 & 95.9 & 93.9-97.4 & 0.016 \\
\hline & 4 & 838 & 96.7 & $95.2-97.8$ & 0.270 \\
\hline & 5 & 1918 & 94.2 & $93.0-95.2$ & $<0.0001$ \\
\hline & 6 & 2539 & 92.2 & $91.1-93.2$ & $<0.0001$ \\
\hline \multirow[t]{6}{*}{ Imergard } & 1 & 645 & 89.3 & $86.6-91.6$ & 0.0008 \\
\hline & 2 & 204 & 98.0 & $94.9-99.6$ & 0.186 \\
\hline & 3 & 556 & 93.4 & $90.9-95.3$ & 0.612 \\
\hline & 4 & 719 & 95.3 & $93.4-96.7$ & 0.956 \\
\hline & 5 & 2098 & 95.5 & $94.5-96.3$ & 0.0013 \\
\hline & 6 & 2658 & 91.0 & $90.4-92.5$ & $<0.0001$ \\
\hline \multirow[t]{6}{*}{ DeltaM+ ImG ${ }^{\mathrm{e}}$} & 1 & 587 & 94.2 & $92.0-96.0$ & $>0.05$ \\
\hline & 2 & 257 & 98.1 & $95.4-99.5$ & 0.137 \\
\hline & 3 & 527 & 92.2 & $89.6-94.4$ & $>0.05$ \\
\hline & 4 & 678 & 94.2 & $92.2-95.9$ & 0.341 \\
\hline & 5 & 1760 & 96.8 & $95.8-97.5$ & 0.315 \\
\hline & 6 & 2163 & 95.9 & $95.0-96.7$ & 0.723 \\
\hline
\end{tabular}

a Percentage of mosquitoes in the hut that were found in the blood-fed state. ${ }^{b}$ Total number of mosquitoes collected in huts for each month indicated. ${ }^{\mathrm{c}} \mathrm{CI}$, confidence interval. ${ }^{\mathrm{d}}$ Two-proportion Z-test, $\alpha=0.05$. ${ }^{\mathrm{e}}$ Deltamethrin and Imergard ${ }^{\mathrm{TM}} \mathrm{WP}$ mixed together and then sprayed.

\subsection{Toxicity}

Mortality rates after $72 \mathrm{~h}$ were low with deltamethrin 62.5 SC-PE ranging from $40 \%$ to $45 \%$ during the first four months and decreasing to about $25 \%$ for months five and six (Figure 3 ). On the other hand, high mortality rates were recorded over a period of six months for ImG ranging from $79 \%$ to $82 \%$. The mixture of ImG and deltamethrin 62.5 SC-PE average mortality rate was $78 \%$. The mortality rate for the treatments containing ImG alone, the mixture, and deltamethrin $62.5 \mathrm{SC}$-PE alone increased during the bioassay from 24 to $48 \mathrm{~h}$ and then from 48 to $72 \mathrm{~h}$ (Figure 3). 


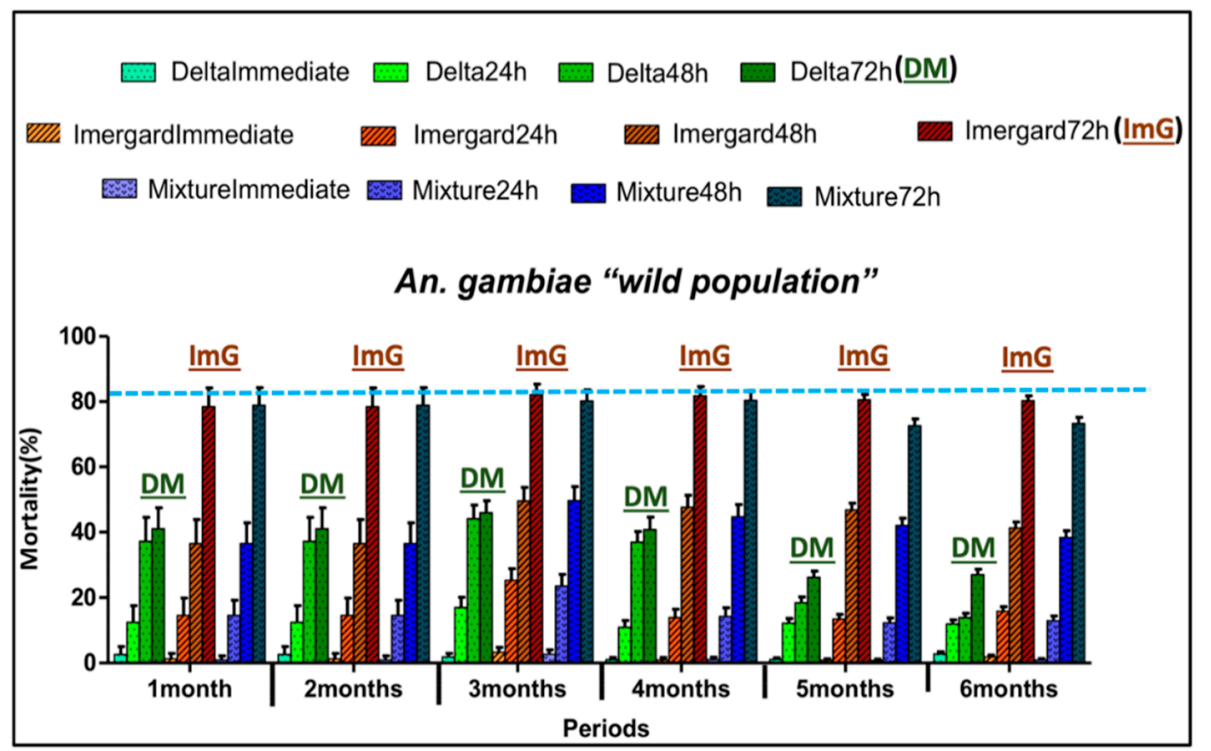

Figure 3. Monthly mortality rates of free-flying resistant Anopheles gambiae (s.l.) entering experimental huts in Cove, Benin. For each treatment, mortality was recorded at collection time (immediate) and then at 24,48 , and $72 \mathrm{~h}$ after collection. Error bars represent $95 \%$ confidence intervals. Delta and $\mathrm{DM}=$ Deltamethrin; ImG = Imergard ${ }^{\mathrm{TM}} \mathrm{WP} ;$ Mixture $=$ Deltamethrin + Imergard ${ }^{\mathrm{TM}} \mathrm{WP}$. The blue dotted line indicates highest mortality rates obtained in mosquitoes collected in the huts.

\subsection{Insecticide Residual Activity}

The residual efficacy of each treatment was determined monthly by exposing pyrethroid susceptible and wild-type (pyrethroid-resistant) mosquitoes to treated walls. The WHO benchmark for bio-efficacy for a residual wall spray is $80 \%$ mortality [23]. For the susceptible "Kisumu" strain, at $48 \mathrm{~h}$, the deltamethrin 62.5 SC-PE mortality was greater than $80 \%$ for the first four months and then decreased to about $45 \%$ in the last two months of the study (Figure 4). The huts treated with Imergard ${ }^{\mathrm{TM}}$ WP showed mortality greater than $80 \%$ for five months with a slight decrease in the last month. Mortality remained above $80 \%$ for the mixture of $\operatorname{ImG}+$ deltamethrin 62.5 SC-PE for the entire study (Figure 4). With the wild An. gambiae (s.l.) population and for the same time point ( $48 \mathrm{~h}$ ), the mortality was low and never exceeded $45 \%$ with deltamethrin 62.5 SC-PE (Figure 5). With ImG and the mixture, the mortality rates remained above $80 \%$ for five months and decreased to about $78 \%$ in the sixth month (Figure 5). Imergard ${ }^{\mathrm{TM}} \mathrm{WP}$ had 3.1 times greater residual activity than the deltamethrin 62.5 SC-PE alone for the first four months and had 5.7-fold greater efficacy at six months against wild-type mosquitoes. In these studies, mortality due to Imergard ${ }^{\mathrm{TM}} \mathrm{WP}$ alone or as a mixture with deltamethrin 62.5 SC-PE increased during the bioassay from 24 to $48 \mathrm{~h}$. These results demonstrated that an MI made from volcanic rock is a suitable alternative to deltamethrin as a residual wall spray. 


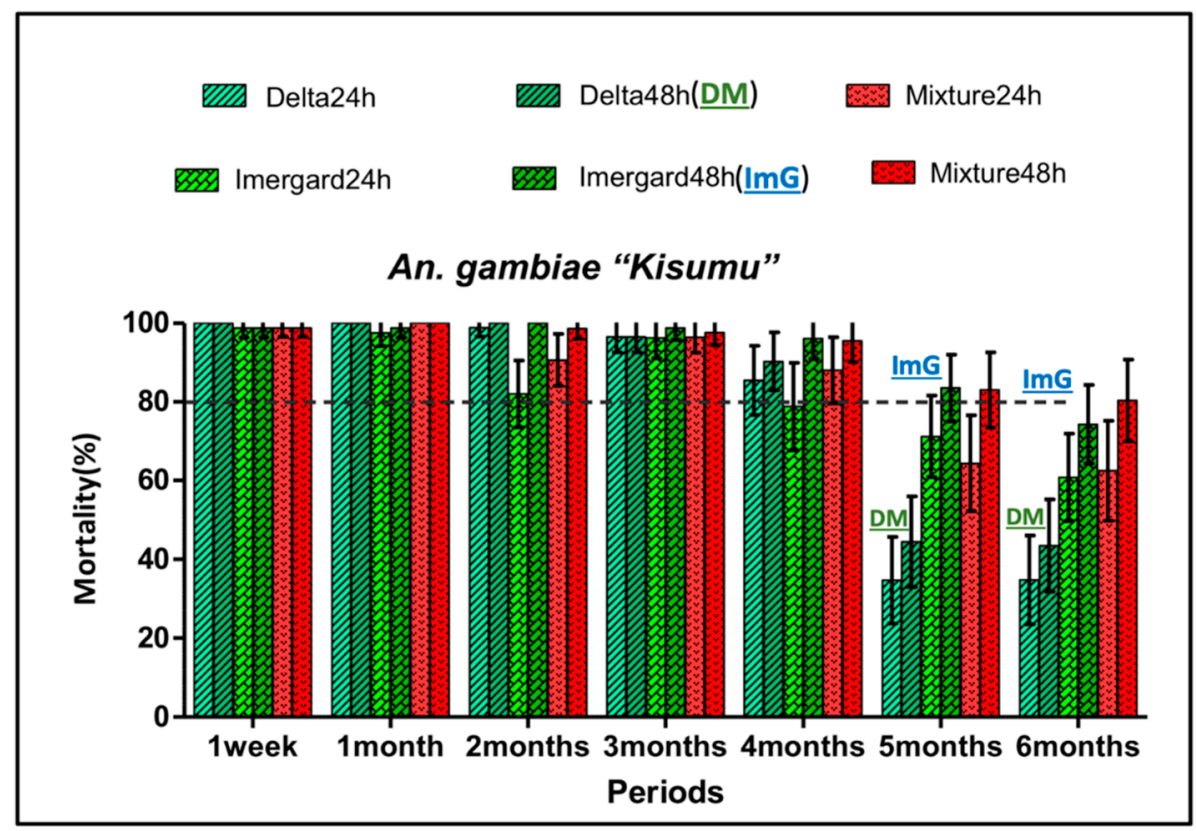

Figure 4. Residual mortality of Imergard ${ }^{\mathrm{TM}} \mathrm{WP}$, deltamethrin, and their mixture following cone bioassays with laboratory susceptible Anopheles gambiae "Kisumu" strain in experimental huts in Cove, Benin. For each treatment, mortality was recorded at 24 and $48 \mathrm{~h}$ after a $30 \mathrm{~min}$ exposure to the walls. Error bars represent $95 \%$ confidence intervals. Delta and DM = Deltamethrin; ImG = Imergard ${ }^{\mathrm{TM}} \mathrm{WP}$; Mixture $=$ Deltamethrin + Imergard $^{\mathrm{TM}}$ WP. The gray dotted line indicates the $80 \%$ threshold requirement of the WHO for residual activity.

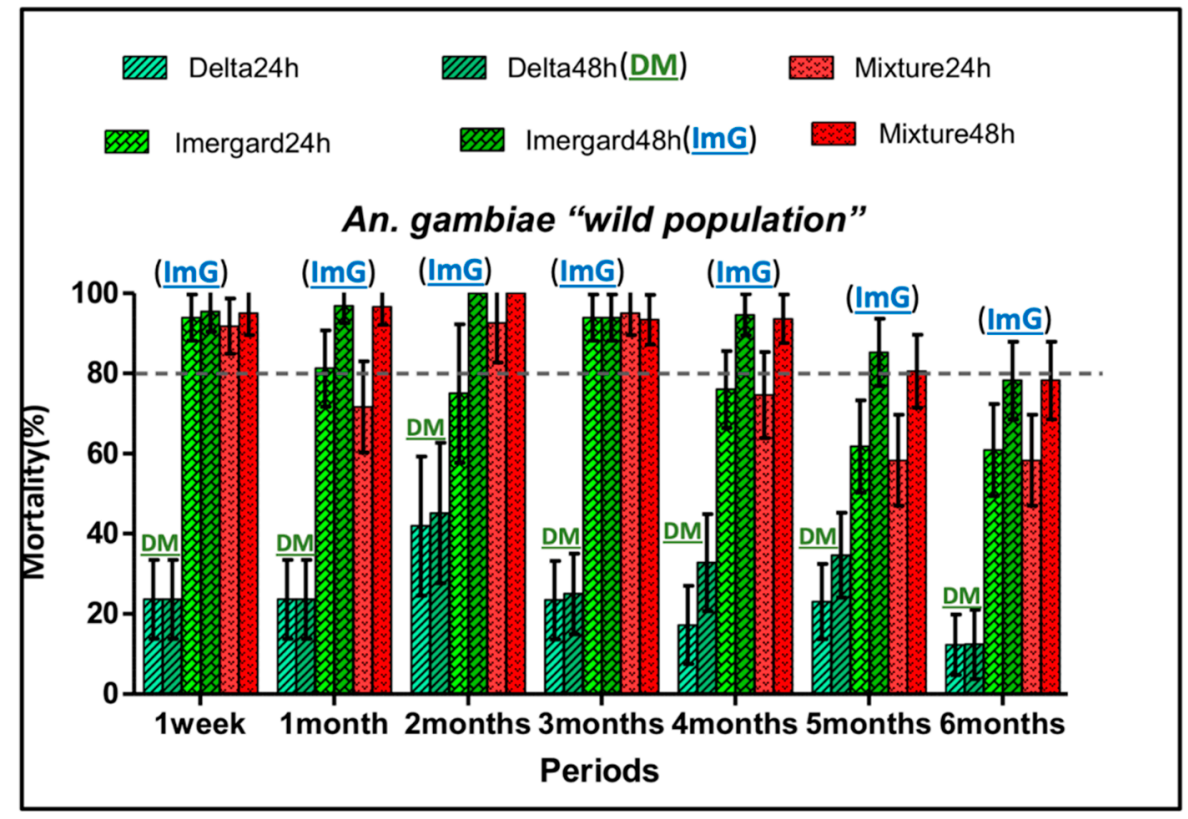

Figure 5. Residual mortality of Imergard ${ }^{\mathrm{TM}} \mathrm{WP}$, deltamethrin, and their mixture following cone bioassays with wild resistant Anopheles gambiae (s.l.) in experimental huts in Cove, Benin. For each treatment, mortality was recorded at 24 and $48 \mathrm{~h}$ after a $30 \mathrm{~min}$ exposure to the walls. Error bars represent $95 \%$ confidence intervals. Delta and DM = Deltamethrin; $\mathrm{ImG}=$ Imergard ${ }^{\mathrm{TM}} \mathrm{WP}$; Mixture $=$ Deltamethrin + Imergard ${ }^{\mathrm{TM}} \mathrm{WP} . \quad$ The gray dotted line indicates the $80 \%$ threshold requirement of the $\mathrm{WHO}$ for residual activity. 


\section{Discussion}

Mosquito transmitted malaria parasites kill more people each year worldwide than any other single mortality factor, especially affecting children under the age of five and expecting mothers. The WHO African region accounted for $94 \%$ of all malaria deaths in 2018 , while $67 \%(272,000)$ of all malaria deaths worldwide were children under five years [1]. Vector control with chemical-based, insecticide-treated bed nets and chemical-based insecticide (residual) wall sprays is critical to mosquito management and the reduction of malaria, the former including insecticide synergists. It is estimated that the use of insecticide-treated nets and the implementation of indoor residual spraying, taken together, averted over 517 million clinical cases of malaria from 2000 to 2015 [28]. Using a mathematical model to predict the health impact of various IRS products, Sherrard-Smith et al. [29] reported that Actellic ${ }^{\circledR}$ 300CS (an organophosphate) and SumiShield ${ }^{\circledR}$ 50WG (a neonicotinoid) grouped together averted up to 500 clinical cases per 1000 people per year. These predictions were determined for areas with moderate endemicity, high levels of pyrethroid resistance, low bed net use and $80 \%$ IRS coverage. In Benin, two rounds of bendiocarb (a carbamate) spraying in a community trial in 2008-2009 reduced biting rates of pyrethroid-resistant $A n$. gambiae by over $80 \%$ and the parous rate by $70 \%$, while none of the mosquitoes analyzed were infected (entomological inoculation rate $=0$ ) [30].

Since the main pesticides currently used for bed nets are pyrethroid insecticides, the use of residual wall sprays with insecticides with a different mode of action like carbamates, organophosphates, and organochlorines are essential to managing mosquito insecticide resistance to bed nets. Despite this effort, insects are increasingly becoming more resistant to pyrethroids and demonstrating cross-resistance to other insecticides. In fact, insecticide resistance in malaria vectors has been documented for pyrethroids [6,8], organophosphates and carbamates [9,31], and organochlorines [32,33]. Currently, there is a significant effort to develop new chemical insecticides with new modes of action for bed nets and residual wall sprays. As of January 2020, 30 IRS products (24 pyrethroids, 1 neonicotinoid, 2 carbamates, 2 organophosphates, and 1 dual-active ingredient neonicotinoid-pyrethroid) as well as 19 ITN kits (18 pyrethroid-based and 1 dual-active ingredient alpha-cypermethrin-chlorfenapyr) have WHO prequalification listings (https://www.who.int/pq-vector-control/prequalified-lists/en, accessed on 24 April 2020). SumiShield ${ }^{\circledR} 50 \mathrm{WG}$, for example, is a new IRS product (WHO prequalification achieved in October 2017) containing clothianidin, a neonicotinoid [22]. If alternatives are not found, we will lose mosquito control not only from wall sprays but also for bed nets, and the gains achieved in the last ten years in the reduction of malaria cases will be reversed.

The other consideration with insecticide-treated bed nets and residual wall sprays is the potential long-term use and exposure of people to chemical insecticides in the home. Contradictory results have been reported in the literature regarding the health effects of IRS insecticides, where some studies found adverse associations between exposure to insecticides such as DDT (dichlorodiphenyltrichloroethane, an organochlorine) and some pyrethroids and human health [34,35], whereas others found none [36,37]. However, the use of chemical insecticides is currently necessary because of the high risk of mortality from contracting malaria, and the insecticides being used have been proven safe. Not only are different modes of action needed for control but effective insecticides from natural sources with more specific action against the mosquito vector would be desirable.

In field trials in Benin, Africa, using WHO-approved huts (Figure 2) and standard WHO methods to evaluate residual wall sprays, ImG alone and as a mixture with deltamethrin (deltamethrin 62.5 SC-PE) was found to be significantly more effective than the pyrethroid alone and the untreated control. A deterrent effect (reduction in mosquito entry rates compared to the control) was found in the first four months (Table 1). The deterrent effect with ImG was not expected as the MI is odorless, and there was no obvious airborne MI in or exiting the experimental huts. One possible explanation is that some of the mosquitoes entering the hut made contact with a treated surface close to the hut entrance and became quiescent. When a mosquito moves, because of their proximity to the opening they have a better chance of exiting compared to the control huts. Because the entrance windows were engineered as one-way openings and deterrence levels were highly variable in different months, this explanation is most likely 
not the mechanism for the calculated ImG deterrence found in some months. Entry reduction rates month to month were highly variable in our study, especially for ImG, and in most cases was less than $10 \%$ when compared to the control. It is most likely that entry reductions could simply be an artifact of the random geographical positioning of the control huts used to calculate deterrence compared to the ImG-treated huts and/or could be the result of environmental differences.

In two-choice repellency studies conducted in laboratory settings at North Carolina State University (NCSU), the malaria mosquito was not repelled by an ImG-treated surface [38]. Results here showed that once mosquitoes were in the hut, Imergard ${ }^{\mathrm{TM}} \mathrm{WP}$ did not repel the mosquitoes into the veranda (Table 2); there was no difference in exophily rates (the proportion of mosquitoes found in the hut veranda) between the control and the MI. This is consistent with the idea that an ImG surface is not repellent. The higher exophily rates observed with deltamethrin alone and the ImG-deltamethrin mixture is expected since pyrethroids are known to demonstrate mosquito spatial repellency [21,39].

No significant blood-feeding inhibition was observed for $\operatorname{ImG}$, the pyrethroid, or the mixture of ImG with the pyrethroid (Table 3). In fact, blood-feeding rates were high in all treatments with $>90 \%$ of the mosquitoes entering the huts acquiring a blood meal in both the treated and untreated huts. This is not uncommon for IRS treatments. No significant differences in blood-feeding rates were found between the treated and untreated huts during the evaluation of chlorfenapyr [21], clothianidin [20,22], and bendiocarb [40] in Benin.

Since there is no physical barrier, host-seeking mosquitoes often feed on the sleeper before landing on the walls to rest and digest their meal [20,22]. High percentages of blood-fed An. gambiae (s.1.) died after resting on the walls treated with Imergard ${ }^{\mathrm{TM}} \mathrm{WP}$ (79-82\% average mortality) and the mixture (73-81\%) during the 1-6-month study (Figure 3), thus confirming this technology has a significant potential as a new active ingredient for IRS. Furthermore, its residual mean activity as a stand-alone treatment was $\geq 80 \%$ mortality for at least five months for both susceptible (Figure 4 ) and resistant (Figure 5) mosquitoes; activity at six months was 76\% and 78\%, respectively (although the 95\% upper confidence interval exceeds $80 \%$ ). Although further studies are needed, it is possible that $80 \%$ mortality could be achieved past six months using the application rate in this study and/or increased even further by increasing the application rate. Examining application rates versus control duration for $\geq 80 \%$ mortality is needed in the future. The use of ImG at an optimum application rate for maximum control over time could lead to a reduction in the number of applications needed each year, a reduction in IRS application costs per home, and an increase in the number of homes that could be treated with the resources currently available. Furthermore, since ImG is not subject to thermal degradation, metal roofs can be treated, further improving efficacy. Based on the differences in mortality in the huts over six months, the MI killed 2.5-fold more mosquitoes (5517) than the pyrethroid (2180).

Imergard ${ }^{\mathrm{TM}} \mathrm{WP}$ showed a time-dependent increase in insecticidal activity against mosquitoes from 24 to $72 \mathrm{~h}$. When a mosquito lands on a treated surface, a few particles of the product are statically transferred onto the insect's body. The insect's epicuticle contains lipids to prevent water loss [41,42]. Current understanding is that the lipid layer is disrupted by the mechanical insecticide. This increases water loss, disrupts the osmolality of the hemolymph, and results in death. The disruption of the lipid layer of the insect's cuticle is the presumed mechanism of action for MIs $[16,17,41]$, and this process can take a few hours to a couple of days depending on the MI, the insect species, dose, environmental conditions (temperature and humidity), and the time since the last consumption of water or a blood meal. This delayed effect was also noticed with non-pyrethroid insecticides in IRS trials, e.g., with clothianidin (a neonicotinoid) [20] and chlorfenapyr (a pyrrole) [21]. It is therefore important that the WHO IRS insecticide evaluation guidelines, originally conceived for fast-acting insecticides, be reviewed or adjusted to account for the varying modes of action of new IRS alternatives currently being investigated.

Mosquitoes exposed to Imergard in the residual activity tests died at a faster and higher rate than the mosquitoes collected inside the huts. In the latter, mosquitoes entered freely and, once inside the huts, had the possibility of moving to different surfaces of the huts and into the exit traps. Some of 
these surfaces were untreated. In the residual efficacy tests, mosquitoes were confined to a small space (WHO cones) presumably increasing their exposure to the treated surface for $30 \mathrm{~min}$, and the mosquitoes may have acquired a higher amount of the insecticide in a shorter period. In laboratory studies, when An. gambiae were continuously exposed to Imergard in cones, 50\% of the mosquitoes were dead in $5 \mathrm{~h}$ [38].

During the study, mosquitoes were not provided access to a $10 \%$ honey-in-water solution during the holding period. The sugar solution fed to mosquitoes used in the residual activity tests prior to their use in this study and the high blood-feeding rates (>90\%) in mosquitoes collected inside the huts allowed them to survive without dying from starvation for the time course of the bioassays [43-45]. Blood feeding may have also decreased the rate of death during holding for the hut-collected mosquitoes. The MI could easily be washed away or become wet during prolonged interactions of the mosquito with a water source in their holding container. The close housing of mosquitoes within a few $\mathrm{cm}$ of a water source, comprised of a large wet surface area optimized for mosquito availability and feeding, creates artificial conditions not found under field conditions. For mechanical insecticides, water provisioning in confinement artificially blocks their mode of action. This is an important example where having rigid testing guidelines for evaluating new IRS technology requiring water for the mosquito might prevent the discovery and implementation of a new mode of action.

A legitimate concern could be that, in houses, access to wet environments might be possible and could reduce or prevent Imergard ${ }^{\mathrm{TM}}$ WP action. However, this is not de facto true. After blood feeding, endophilic/anthropophilic mosquitoes seek a protected resting site inside the house (or sometimes outside) where they can digest the blood meal and develop eggs. At least $50 \%$ of An. gambiae females stay inside the home after a blood meal and invade interior walls, crevices, furniture, etc., for that purpose [46]. This stage of the gonotrophic cycle takes 1.8 days up to several days, where the duration varies depending on the mosquito species, the amount of blood consumed, and the environmental conditions [46-49]. Because blood digestion and egg maturation occur at rest with little to no interaction with a water source, it is likely that under natural conditions in a home the MI would have produced its lethal effect before the mosquito finished blood meal digestion and began to seek an oviposition site.

One concern about the use of a mechanical insecticide on the walls of a home is that human contact with treated surfaces might prematurely reduce the duration of control. A possible solution could be to treat only the upper part of the walls or target places where mosquitoes rest, such as crevices. Djenontin et al. [50] showed that covering only the upper one-third of the wall of huts with a carbamate-treated plastic sheeting (CTPS) provided equal or better efficacy compared to a traditional IRS application method using bendiocarb.

Improved toxicity and residual activity were obtained by mixing deltamethrin with ImG compared to deltamethrin alone especially for wild-type insecticide-resistant An. gambiae (Figures 3-5). Mixing two insecticides with different modes of actions to improve vector control even in areas of resistance was suggested before and recommended [6]; using two different modes of action could delay the evolution of resistance or reverse current levels of resistance. The WHO recommends that the two insecticides be co-formulated into a single product [6].

The poor performance observed with deltamethrin in our study (even though not surprising) is worrisome. Deltamethrin 62.5 SC-PE (a.i. $62.5 \mathrm{~g} / \mathrm{L}$ deltamethrin; Bayer, WHOPES recommendations achieved in September 2013) is a polymer-enhanced suspension concentrate that came on the market only a few years ago and has been shown in several studies to be more effective than the standard deltamethrin WG25 against both susceptible and wild resistant mosquitoes [51,52]. The work here is suggesting that improving current active ingredients by formulation alone will not be sufficient in resolving resistance issues for the long term and that new active ingredients with a different mode of action are needed. 


\section{Conclusions}

In summary, the use of a mechanical insecticide derived from volcanic glass represents a new paradigm for mosquito and malaria control. Applied as a stand-alone treatment or as a mixture with deltamethrin, Imergard ${ }^{\mathrm{TM}}$ WP provided $\geq 80 \%$ control for five months for both susceptible and pyrethroid-resistant Anopheles mosquitoes in Africa with the likelihood of even longer-term activity. Activity at six months was $76 \%$ and $78 \%$, respectively. Due to its new mode of action (in vector control), natural origin, safety (mammalian toxicity $>10 \mathrm{~g} / \mathrm{kg}$ ) [18], abundance in nature, and low estimated cost, ImG should be an effective non-chemical alternative to current insecticides used in IRS. Imergard ${ }^{\mathrm{TM}} \mathrm{WP}$, because of its mechanical mechanism of action, has a low probability of increasing insecticide resistance to chemical insecticides and therefore can be a powerful tool for integrated resistance management in Africa. The MI easily mixes with water and is applied using standard vector control spray equipment. This represents the first report on the practical use of a mineral in the field for mosquito control in Africa. More studies are needed to fully understand the potential of this new technology.

Author Contributions: J.M.D., F.R.A., and R.A. (Roseric Azondekon) designed the study in Africa; J.M.D., C.S.A., R.M.R., M.G.M., and D.A.S. secured funding; D.A.S., B.W., D.G., and L.T. provided field technical assistance for the Imergard ${ }^{\mathrm{TM}}$ WP application; J.M.D., G.G.P., J.A., B.N., and R.A. (Rodrigue Anagonou) carried out the experiments in Benin; M.C.A. supervised the Benin study. J.M.D., R.A. (Roseric Azondekon), and B.A. analyzed the data; J.M.D. drafted the manuscript. J.M.D., R.A. (Roseric Azondekon), F.R.A., C.S.A., M.G.M., and R.M.R. critically revised the manuscript. All authors have read and agreed to the published version of the manuscript.

Funding: The study was funded by Imerys (Imerys Filtration Minerals, Inc., Roswell, GA, 30076, USA). J.M.D. was funded by a Fulbright scholarship to study in the USA; a teaching/research assistantship in the Department of Entomology and Plant Pathology and the Department of Biological Sciences at North Carolina (NC) State University; a one semester research assistantship from Imerys; and a postdoctoral research position from a DWFP grant awarded to R.M.R., C.S.A., and M.G.M. (W911QY1910003). R.M.R. and C.S.A. were supported by the North Carolina Agricultural Research Station.

Acknowledgments: We thank Didier Ikue, Romain Goumabou, and Rodolphe Kossou for their assistance at the initiation of the study. We are also grateful to all the volunteer sleepers from Cove for their participation in this study.

Conflicts of Interest: The authors declare no conflict of interest.

\section{References}

1. WHO. World Malaria Report 2019; World Health Organization: Geneva, Switzerland, 2019; ISBN 978-924-156572-1.

2. Mashauri, F.M.; Manjurano, A.; Kinung'hi, S.; Martine, J.; Lyimo, E.; Kishamawe, C.; Ndege, C.; Ramsan, M.M.; Chan, A.; Mwalimu, C.D.; et al. Indoor residual spraying with micro-encapsulated pirimiphos-methyl (Actellic ${ }^{\circledR}$ 300CS) against malaria vectors in the Lake Victoria basin, Tanzania. PLoS ONE 2017, 12, e0176982. [CrossRef]

3. Mnzava, A.P.; Knox, T.B.; Temu, E.A.; Trett, A.; Fornadel, C.; Hemingway, J.; Renshaw, M. Implementation of the global plan for insecticide resistance management in malaria vectors: Progress, challenges and the way forward. Malar. J. 2015, 14, 173. [CrossRef] [PubMed]

4. Kitau, J.; Oxborough, R.; Matowo, J.; Mosha, F.; Magesa, S.M.; Rowland, M. Indoor residual spraying with microencapsulated DEET repellent (N, N-diethyl-m-toluamide) for control of Anopheles arabiensis and Culex quinquefasciatus. Parasit. Vectors 2014, 7, 446. [CrossRef] [PubMed]

5. Dengela, D.; Seyoum, A.; Lucas, B.; Johns, B.; George, K.; Belemvire, A.; Caranci, A.; Norris, L.C.; Fornadel, M. Multi-country assessment of residual bio-efficacy of insecticides used for indoor residual spraying in malaria control on different surface types: Results from program monitoring in 17 PMI/USAID-supported IRS countries. Parasit. Vectors 2018, 11, 71. [CrossRef] [PubMed]

6. WHO. Global Plan for Insecticide Resistance Management in Malaria Vectors (GPIRM); World Health Organization: Geneva, Switzerland, 2012.

7. Agossa, F.R.; Gnanguenon, V.; Anagonou, R.; Azondékon, R.; Aïzoun, N.; Sovi, A.; Oke-Agbo, F.; Sèzonlin, M.; Akogbéto, M.C. Impact of insecticide resistance on the effectiveness of pyrethroid-based malaria vectors 
control tools in Benin: Decreased toxicity and repellent effect. PLoS ONE 2015, 10, e0145207. [CrossRef] [PubMed]

8. Wilson, A.L.; Pinder, M.; Bradley, J.; Donnelly, M.J.; Hamid-Adiamoh, M.; Jarju, L.B.; Jawara, M.; Jeffries, D.; Kandeh, B.; Rippon, E.J.; et al. Emergence of knock-down resistance in the Anopheles gambiae complex in the Upper River Region, The Gambia, and its relationship with malaria infection in children. Malar. J. 2018, 17, 205. [CrossRef]

9. Aikpon, R.; Sèzonlin, M.; Ossè, R.; Akogbéto, M. Evidence of multiple mechanisms providing carbamate and organophosphate resistance in field An. gambiae population from Atacora in Benin. Parasit. Vectors 2014, 7, 568. [CrossRef]

10. Hemingway, J.; Ranson, H. Insecticide resistance in insect vectors of human disease. Annu. Rev. Entomol. 2000, 45, 371-391. [CrossRef]

11. Soko, W.; Chimbari, M.J.; Mukaratirwa, S. Insecticide resistance in malaria-transmitting mosquitoes in Zimbabwe: A review. Infect. Dis. Poverty 2015, 4, 46. [CrossRef]

12. Athanassiou, C.G.; Vayias, B.J.; Dimizas, C.B.; Kavallieratos, N.G.; Papagregoriou, A.S.; Buchelos, C.T. Insecticidal efficacy of diatomaceous earth against Sitophilus oryzae (L.) (Coleoptera: Curculionidae) and Tribolium confusum du Val (Coleoptera: Tenebrionidae) on stored wheat: Influence of dose rate, temperature and exposure interval. J. Stored Prod. Res. 2005, 41, 47-55. [CrossRef]

13. El-Aziz, S.E.A. Laboratory and field Evaluation of Kaolin and Bentonite particle films against onion thrips, Thrips tabaci (Lind.) (Thysanoptera: Thripidae) on onion plants. J. Appl. Sci. Res. 2013, 9, 3141-3145.

14. Alavo, T.B.; Yarou, B.B.; Atachi, P. Field effects of kaolin particle film formulation against major cotton lepidopteran pests in North Benin, West Africa. Int. J. Pest. Manag. 2010, 56, 287-290. [CrossRef]

15. Saour, G. Efficacy of kaolin particle film and selected synthetic insecticides against pistachio psyllid Agonoscena targionii (Homoptera: Psyllidae) infestation. Crop. Prot. 2005, 24, 711-717. [CrossRef]

16. Islam, M.S.; Rahman, M.M. Diatomaceous earth induced alterations in the reproductive attributes in the housefly Musca domestica L. (Diptera: Culicidae). Elixir Appl. Zool. 2016, 96, 41241-41244.

17. Luz, C.; Rodrigues, J.; Rocha, L.F. Diatomaceous earth and oil enhance effectiveness of Metarhizium anisopliae against Triatoma infestans. Acta Trop. 2012, 122, 29-35. [CrossRef] [PubMed]

18. Maxim, L.D.; Niebo, R.; McConnell, E.E. Perlite toxicology and epidemiology-A review. Inhal. Toxicol. 2014, 26, 259-270. [CrossRef] [PubMed]

19. Korunic, Z. Diatomaceous Earths, a group of natural insecticides. J. Stored Prod. Res. 1998, 34, 87-97. [CrossRef]

20. Ngufor, C.; Fongnikin, A.; Rowland, M.; N'Guessan, R. Indoor residual spraying with a mixture of clothianidin (a neonicotinoid insecticide) and deltamethrin provides improved control and long residual activity against pyrethroid resistant Anopheles gambiae sl in Southern Benin. PLoS ONE 2017, 12, e0189575. [CrossRef]

21. Ngufor, C.; Critchley, J.; Fagbohoun, J.; N'Guessan, R.; Todjinou, D.; Rowland, M. Chlorfenapyr (a pyrrole insecticide) applied alone or as a mixture with alpha-cypermethrin for indoor residual spraying against pyrethroid resistant Anopheles gambiae sl: An experimental hut study in Cove, Benin. PLoS ONE 2016, 11, e0162210. [CrossRef]

22. Agossa, F.R.; Padonou, G.G.; Koukpo, C.Z.; Zola-Sahossi, J.; Azondekon, R.; Akuoko, O.K.; Ahoga, J.; N'dombidje, B.; Akinro, B.; Jacques, A.; et al. Efficacy of a novel mode of action of an indoor residual spraying product, SumiShield ${ }^{\circledR} 50 \mathrm{WG}$ against susceptible and resistant populations of Anopheles gambiae (s.1.) in Benin, West Africa. Parasit. Vectors 2018, 11, 293. [CrossRef]

23. WHO. Guidelines for Testing Mosquito Adulticides for Indoor Residual Spraying and Treatment of Mosquito Nets; World Health Organization: Geneva Switzerland, 2006.

24. Hougard, J.M.; Martin, T.; Guillet, P.F.; Coosemans, M.; Itoh, T.; Akogbeto, M.; Chandre, F. Preliminary field testing of a long-lasting insecticide-treated hammock against Anopheles gambiae and Mansonia spp. (Diptera: Culicidae) in West Africa. J. Med. Entomol. 2007, 44, 651-655. [CrossRef] [PubMed]

25. Gillies, M.T.; De Meillon, B. The Anophelinae of Africa south of the Sahara. S. Afr. Inst. Med. Res. 1968, 54, $1-343$.

26. Abbott, W.S. A method of computing the effectiveness of an insecticide. J. Econ. Entomol. 1925, 18, $265-267$. [CrossRef]

27. R Development Core Team. R: A language and Environment for Statistical Computing; R Foundation for Statistical Computing: Vienna, Austria, 2016. 
28. Bhatt, S.; Weiss, D.J.; Cameron, E.; Bisanzio, D.; Mappin, B.; Dalrymple, U.; Battle, K.E.; Moyes, C.L.; Henry, A.; Eckhoff, P.A.; et al. The effect of malaria control on Plasmodium falciparum in Africa between 2000 and 2015. Nature 2015, 526, 207-211. [CrossRef] [PubMed]

29. Sherrard-Smith, E.; Griffin, J.T.; Winskill, P.; Corbel, V.; Pennetier, C.; Djenontin, A.; Moore, S.; Richardson, J.H.; Müller, P.; Edi, C.; et al. Systematic review of indoor residual spray efficacy and effectiveness against Plasmodium falciparum in Africa. Nat. Commun. 2018, 9, 4982. [CrossRef] [PubMed]

30. Akogbeto, M.; Padonou, G.G.; Bankole, H.S.; Gazard, D.K.; Gbedjissi, G.L. Dramatic decrease in malaria transmission after large-scale indoor residual spraying with Bendiocarb in Benin, an area of high resistance of Anopheles gambiae to pyrethroids. Am. J. Trop. Med. Hyg. 2011, 85, 586-593. [CrossRef] [PubMed]

31. Aïkpon, R.; Aïzoun, N.; Sovi, A.; Oussou, O.; Govoetchan, R.; Gnaguenon, V.; Oke-Agbo, F.; Osse, R.; Akogbeto, M. Increase of Ace-1 resistance allele in the field population of Anopheles gambiae following a large-scale indoor spraying (IRS) implementation using bendiocarb in Atacora region in Benin, West Africa. J. Cell Anim. Biol. 2014, 8, 15-22.

32. Oduola, A.O.; Olejebe, J.B.; Ashiegbu, C.O.; Adeogun, A.O.; Otubanjo, O.A.; Awolola, T.S. High level of DDT resistance in the malaria mosquito: Anopheles gambiae s.l. from rural, semi urban and urban communities in Nigeria. J. Rural. Trop. Pub. Health 2010, 9, 114-120.

33. Ranson, H.; Jensen, B.; Vulule, J.M.; Wang, X.; Hemingway, J.; Collins, F.H. Identification of a point mutation in the voltage-gated sodium channel gene of Kenyan Anopheles gambiae s.s. associated with resistance to DDT and pyrethroids. Ins. Mol. Biol. 2000, 9, 491-497. [CrossRef]

34. Murray, J.; Eskenazi, B.; Bornman, R.; Gaspar, F.W.; Crause, M.; Obida, M.; Chevrier, J. Exposure to DDT and hypertensive disorders of pregnancy among South African women from an indoor residual spraying region: The VHEMBE study. Environ. Res. 2018, 162, 49-54. [CrossRef]

35. Eskenazi, B.; An, S.; Rauch, S.A.; Coker, E.S.; Maphula, A.; Obida, M.; Crause, M.; Kogut, K.R.; Bornman, R.; Chevier, J. Prenatal exposure to DDT and pyrethroids for malaria control and child neurodevelopment: The VHEMBE cohort, South Africa. Environ. Health Perspect. 2018, 126, 047004. [CrossRef] [PubMed]

36. Pan, I.J.; Daniels, J.L.; Goldman, B.D.; Herring, A.H.; Siega-Riz, A.M.; Rogan, W.J. Lactational exposure to polychlorinated biphenyls, dichlorodiphenyltrichloroethane, and dichlorodiphenyldichloroethylene and infant neurodevelopment: An analysis of the pregnancy, infection, and nutrition babies study. Environ. Health Perspect. 2009, 117, 488-494. [CrossRef] [PubMed]

37. Gaspar, F.W.; Harley, K.G.; Kogut, K.; Chevrier, J.; Mora, A.M.; Sjodin, A.; Eskenazi, B. Prenatal DDT and DDE exposure and child IQ in the CHAMACOS cohort. Environ. Int. 2015, 85, 206-212. [CrossRef]

38. Deguenon, J.M.; Riegel, C.; Cloherty-Duvernay, E.R.; Stewart, D.A.; Wand, B.; Gittins, D.; Tihomirov, L.; Apperson, C.S.; McCord, M.G.; Roe, R.M. New mosquitocide derived from volcanic rock. J. Med. Entomol. under review.

39. Agossa, F.R.; Aïkpon, R.; Azondekon, R.; Govoetchan, R.; Padonou, G.G.; Oussou, O.; Oke-Agbo, F.; Akogbeto, M.C.A. Efficacy of various insecticides recommended for indoor residual spraying: Pirimiphos methyl, potential alternative to bendiocarb for pyrethroid resistance management in Benin, West Africa. Trans. R. Soc. Trop. Med. Hyg. 2014, 108, 84-91. [CrossRef] [PubMed]

40. Akogbeto, M.C.; Padonou, G.G.; Gbenou, D.; Irish, S.; Yadouleton, A. Bendiocarb, a potential alternative against pyrethroid resistant Anopheles gambiae in Benin, West Africa. Malar. J. 2010, 9, 204. [CrossRef] [PubMed]

41. Ebeling, W.; Wagner, R.E. Rapid desiccation of drywood termites with inert sorptive dusts and other substances. J. Econ. Entomol. 1959, 52, 190-207. [CrossRef]

42. Lockey, K.H. Lipids of the insect cuticle: Origin, composition and function. Comp. Biochem. Physiol. Part B Comp. Biochem. 1988, 89, 595-645. [CrossRef]

43. Nayar, J.K.; Sauerman, D.M., Jr. The effects of nutrition on survival and fecundity in Florida mosquitoes: Part 1. Utilization of sugar for survival. J. Med. Entomol. 1975, 12, 92-98. [CrossRef]

44. Nayar, J.K.; Sauerman, D.M., Jr. The effects of nutrition on survival and fecundity in Florida mosquitoes: Part 2. Utilization of a blood meal for survival. J. Med. Entomol. 1975, 12, 99-103. [CrossRef]

45. Gary, R.E., Jr.; Woodbridge, A.F. Effects of available sugar on the reproductive fitness and vectorial capacity of the malaria vector Anopheles gambiae (Diptera: Culicidae). J. Med. Entomol. 2001, 36, 22-28. [CrossRef] [PubMed] 
46. Carnevale, P.; Robert, V. Les Anophèles: Biologie, Transmission du Plasmodium et Lutte Antivectorielle; IRD éditions: Marseille, France, 2009; p. 402.

47. Rúa, G.L.; Quiñones, M.L.; Vélez, I.D.; Zuluaga, J.S.; Rojas, W.; Poveda, G.; Ruiz, D. Laboratory estimation of the effects of increasing temperatures on the duration of gonotrophic cycle of Anopheles albimanus (Diptera: Culicidae). Mem. Inst. Oswaldo Cruz. 2005, 100, 515-520. [CrossRef] [PubMed]

48. Dana, A.N.; Hong, Y.S.; Kern, M.K.; Hillenmeyer, M.E.; Harker, B.W.; Lobo, N.F.; Hogan, J.R.; Romans, P.; Collins, F.H. Gene expression patterns associated with blood-feeding in the malaria mosquito Anopheles gambiae. BMC Genom. 2005, 6, 5. [CrossRef] [PubMed]

49. Lardeux, F.J.; Tejerina, R.H.; Quispe, V.; Chavez, T.K. A physiological time analysis of the duration of the gonotrophic cycle of Anopheles pseudopunctipennis and its implications for malaria transmission in Bolivia. Malar. J. 2008, 7, 141. [CrossRef] [PubMed]

50. Djenontin, A.; Chandre, F.; Dabiré, K.R.; Chabi, J.; N'Guessan, R.; Baldet, T.; Akogbeto, M.; Corbel, V. Indoor use of plastic sheeting impregnated with carbamate combined with long-lasting insecticidal mosquito nets for the control of pyrethroid-resistant malaria vectors. Am. J. Trop. Med. Hyg. 2010, 83, 266-270. [CrossRef]

51. Oxborough, R.M.; Kitau, J.; Jones, R.; Mosha, F.W.; Rowland, M.W. Experimental hut and bioassay evaluation of the residual activity of a polymer-enhanced suspension concentrate (SC-PE) formulation of deltamethrin for IRS use in the control of Anopheles arabiensis. Parasit. Vectors 2014, 7, 454. [CrossRef]

52. Dunford, J.C.; Estep, A.S.; Waits, C.M.; Richardson, A.G.; Hoel, D.F.; Horn, K.; Walker, T.W.; Blersch, J.S.; Kerce, J.D.; Wirtz, R.A. Evaluation of the long-term efficacy of K-Othrine ${ }^{\circledR}$ PolyZone on three surfaces against laboratory reared Anopheles gambiae in semi-field conditions. Malar. J. 2018, 17, 94. [CrossRef]

(C) 2020 by the authors. Licensee MDPI, Basel, Switzerland. This article is an open access article distributed under the terms and conditions of the Creative Commons Attribution (CC BY) license (http://creativecommons.org/licenses/by/4.0/). 